\title{
Lung Adenocarcinoma with Mixed Bronchioloalveolar and Invasive Components
}

National Cancer Institute

\section{Source}

National Cancer Institute. Lung Adenocarcinoma with Mixed Bronchioloalveolar and

Invasive Components. NCI Thesaurus. Code C65197.

A lung adenocarcinoma consisting of a bronchioloalveolar component and an invasive adenocarcinomatous component. 